\title{
Variable use of amiodarone is associated with a greater risk of recurrence of atrial fibrillation in the critically ill
}

\author{
Goran Mitrić ${ }^{1}$, Andrew Udy ${ }^{4,5}$, Hiran Bandeshe ${ }^{2}$, Pierre Clement ${ }^{2}$ and Rob Boots ${ }^{2,3^{*}}$
}

\begin{abstract}
Background: Atrial fibrillation is a common rhythm disturbance in the general medical-surgical intensive care unit. Amiodarone is a popular drug in this setting but evidence to inform clinical practice remains scarce. We aimed to identify whether variation in the clinical use of amiodarone was associated with recurrent atrial fibrillation.

Methods: This was a retrospective audit of 177 critically ill patients who developed new-onset atrial fibrillation after admission to a tertiary level medical-surgical trauma intensive care unit. Patterns of amiodarone prescription (including dosage schedule and duration) were assessed in relation to recurrence of atrial fibrillation during the intensive care unit stay. Known recurrence risk factors, such as inotrope administration, cardiac disease indices, Charlson Comorbidity Index, magnesium concentrations, fluid balance, and potassium concentrations, were also included in adjusted analysis using forward stepwise logistic regression modelling.

Results: The cohort had a median (interquartile range) age of 69 years (60-75), Acute Physiology and Chronic Health Evalution II score of 22 (17-28) and Charlson Comorbidity Index of 2 (1-4). A bolus dose of amiodarone followed by infusion $(P=0.02$ ), in addition to continuing amiodarone infusion through to discharge from the intensive care unit $(P<0.001)$, were associated with less recurrent dysrhythmia. Recurrence after successful treatment was associated with ceasing amiodarone while an inotrope infusion continued $(P<0.001)$, and was more common in patients with a prior history of congestive cardiac failure $(P=0.04)$, and a diagnosis of systemic inflammatory response syndrome $(P=0.02)$.

Conclusions: Amiodarone should be administered as a bolus dose followed immediately with an infusion when treating atrial fibrillation in the medical-surgical intensive care unit. Consideration should be given to continuing amiodarone infusions in patients on inotropes until they are ceased.
\end{abstract}

Keywords: Amiodarone, Atrial fibrillation, Critical care, Recurrence

\section{Background}

Atrial fibrillation (AF) is a common cardiac rhythm disturbance encountered in critically ill patients in the general medical or surgical intensive care unit (ICU) [1]. Depending upon the study population, AF is reported to occur at frequencies ranging from $8.3 \%$ to $46 \%$, the latter being associated with patients who have undergone cardiac surgery or were admitted for treatment of sepsis

\footnotetext{
* Correspondence: r.boots@uq.edu.au

2Department of Intensive Care Medicine, Royal Brisbane \& Women's Hospital, Herston, Brisbane, QLD, Australia

${ }^{3}$ Burns Trauma and Critical Care Research Centre, University of Queensland, Brisbane, QLD, Australia

Full list of author information is available at the end of the article
}

[1-9]. The occurrence of AF potentially leads to thromboembolism or haemodynamic compromise [10]. Risk factors for the development of AF in critically ill patients have been predominantly derived from cardiothoracic surgical patients. Data on risk factors for atrial fibrillation in the non-cardiothoracic surgery ICU population are scarce.

Defined risks include: use of catecholamines and positive inotropic drugs $[8,11,12]$, high severity of disease index scores $[1,5,9,13]$, sepsis $[1,5]$, cardiovascular disease $[4,9,12,13]$, electrolyte disturbances [4], advanced age $[9,12,13]$, elevated markers of inflammation $[5,6]$, hypoxia [5], and high central venous pressures [5]. 
Whether part of the patient's prior history, new in onset or recurrent, AF has been shown to be an independent risk factor for mortality in the ICU [3,13-15]. Of note, new-onset AF has been associated with increased diastolic dysfunction, vasopressor use, and a greater cumulative positive fluid balance [15], although similar data are not widely available for recurrent AF in the ICU.

Amiodarone is considered the drug of choice for the treatment of AF in the ICU [16]. Two randomised controlled trials have shown amiodarone to be effective in converting AF into sinus rhythm in this setting $[17,18]$. The efficacy of amiodarone has also been confirmed by other studies showing that it is effective at both converting AF into sinus rhythm [17-20] and controlling ventricular rate $[21,22]$, while being haemodynamically well tolerated [23, 24]. Many dosing regimens have been described with no consensus on the optimal treatment strategy. Therefore, the present study aimed to assess the effect of variation in amiodarone use on dysrhythmia recurrence in patients with new-onset $\mathrm{AF}$ admitted to a non-cardiothoracic ICU.

\section{Methods}

We conducted a retrospective cohort study in a large general medical-surgical ICU over a 24-month period. Data were recorded prospectively in electronic format (IntelliVue Clinical Information Portfolio, Philips Medical Systems, Eindhoven, Netherlands). Patients were eligible for inclusion if they were adults (18 years or older) who developed new-onset AF during their ICU stay and were treated with amiodarone. Exclusion criteria were recent cardiothoracic surgery, inadequate records being available for analysis, previous treatment with amiodarone at any time point prior to entry into the study, and a previous history of atrial fibrillation.

\section{Definitions and data collection}

AF was defined as a rhythm on the electrocardiogram (ECG) with replacement of P waves with rapid oscillations or fibrillatory waves that vary in size, shape and timing, associated with an irregular, frequently rapid, ventricular response when atrioventricular conduction is intact [25]. This was derived from the confirmed hourly recordings of cardiac rhythm from the clinical information system as reported from the algorithm analysis programme of the Phillips IntelliVue IP critical care monitoring system. Successful treatment was defined as conversion of AF into normal sinus rhythm within 12 hours of amiodarone administration. Recurrence was defined as AF identified on the ECG occurring prior to discharge from the ICU following successful conversion of cardiac rhythm from AF into normal sinus rhythm. At the time of $\mathrm{AF}$, the presence of hypomagnesaemia $(\mathrm{Mg}<0.8 \mathrm{mmol} / \mathrm{L})$, hypokalaemia $(\mathrm{K}<3.5 \mathrm{mmol} / \mathrm{L})$, the presence of a systemic inflammatory response syndrome (SIRS) [26], and sepsis (infection as a presumed or proven cause of SIRS) [27], were recorded.

In summarising the use of amiodarone, a bolus was defined as a fixed dose of greater than $150 \mathrm{mg}$ given over 20 minutes to an hour, a continuous infusion was a fixed dose of amiodarone delivered hourly by a syringe pump for more than 2 hours, and delay to an infusion was a gap of 1 hour in the fluid administration record for the administration of a bolus and the commencement of an infusion.

Continuous automated ECG rhythm tracings were recorded for all patients for the entire duration of their ICU stay. Data collection included records of drugs administered (amiodarone and all inotropes), their doses, and infusion rates. Physiologic variables were recorded daily including fluid balance, white cell count, central venous pressure, and temperature. Demographic data included age, gender, weight, height, body mass index (BMI) [28], Acute Physiology and Chronic Health Evaluation II (APACHE II) score [29], Simplified Acute Physiology Score II (SAPS II) [30], ICU admission and discharge times, hospital admission and discharge times, hospital outcome, and ICU outcome. The time and date for AF onset, conversion to normal sinus rhythm, and any recurrence were extracted from ECG data. Data regarding comorbidities were collected using the Charlson Comorbidity Index [31] with both scores and diagnoses recorded. The presence of past rheumatic fever [32], uncontrolled hyperthyroidism, mitral valve disease, haemochromatosis [33], hypertension [34] and concurrent use of digoxin and metoprolol were also recorded. If patients had multiple admissions during the study period only the initial admission in which amiodarone was used for the first time was included in data collection.

The study was granted low-risk research approval by the Human Research Ethics Committee, Royal Brisbane and Women's Hospital as well as the Medical Research Ethics Committee, University of Queensland with individual consent waived due to the retrospective study design (HREC/11/QRBW/292 and 2012000135).

\section{Analysis plan}

Descriptive statistics were calculated for all study variables, with data reported as means or medians with interquartile ranges (IQRs) for continuous data, percentages for categorical data, and $95 \%$ confidence intervals where appropriate. Data were analysed using KruskalWallis and Wilcoxon sign rank tests for continuous data where appropriate. Categorical data were assessed using chi squared or Fisher's exact test where analysis assumptions were met. No assumptions were made for missing data and proportions were adjusted for the number of patients with available data. A two-sided $P$ value of less 
than 0.05 was considered to indicate statistical significance. Forward stepwise logistic regression modelling for variables predictive of recurrence of AF was used. Variables were included if they were recognised as prognostic for recurrence of AF in critically ill patients, or if their $P$ value was $<0.2$ in univariate testing. Discrete variables were included as bipolar outcomes and continuous variables approximated a normal distribution or were collapsed into an ordinal variable. Models were assessed for discrimination using the area under the receiver-operating function and goodness of fit (HosmerLemeshow). Data were analysed using Stata 9 Statistical package (College Station, TX, USA).

\section{Results}

Over the 2-year study period, we identified 520 admissions in which patients were administered amiodarone for AF at some point during their ICU stay. Of these, 186 met criteria for study inclusion. Of these, 86 (49 \%) were successfully treated with amiodarone, without recurrence of AF until discharge from ICU. Nine patients remained in AF until discharge from the ICU and were not considered further in the analysis. In the remaining 91 patients (51\%), there was recurrence of $\mathrm{AF}$ at least once during the ICU stay, after initial successful conversion to normal sinus rhythm (Fig. 1).

The median (IQR) age of patients was 69 years (60-75), they were predominantly male (64\%), with a median APACHE II score of 22 (17-28). Baseline characteristics of patients including demographic information, severity of disease indices and co-morbidities are presented in Tables 1 and 2. Echocardiogram information was only available in 33 patients, too small a number to include in any detailed analysis. All four patients with hyperthyroidism had recurrent AF. Patients with or without recurrent AF concurrently received digoxin (27\% compared to $10 \%, P=0.004$ ) or beta-blockers ( $46 \%$ compared to $53 \%, P=0.37$ ) with all patients receiving digoxin also receiving beta-blockers, reflecting the use of multiple agents to control recurrent AF. The majority of patients received noradrenaline as an inotrope (three without $\mathrm{AF}$ recurrence and five with $\mathrm{AF}$ recurrence received adrenaline). No patients were electrically cardioverted or received dopamine or dobutamine.

Patients with recurrent AF had a higher Charlson Comorbidity Index and were more likely to have a history of cardiac failure (Table 2). Age and severity of illness indices were not significantly associated with recurrence of AF. It was not possible to define a suitable time frame for the comparison of physiological AF risk factors in the group that did not have a recurrence. As such, a within-group analysis of physiological parameters was undertaken in those with recurrent $\mathrm{AF}$, comparing variables at the time of AF recurrence and the time of initial reversion to normal sinus rhythm. For patients with recurrent AF, a less positive 24-hour fluid balance, lower serum magnesium concentrations and a higher white cell count were observed on the day of AF recurrence (Table 3).

There was no uniform treatment strategy with the use of amiodarone (Table 4). In 62 (35\%) patients, no bolus dose or prior administration of amiodarone was recorded. Only 92 (52\%) patients received both bolus dosing and an infusion. The median (IQR) total dose of amiodarone delivered was $905 \mathrm{mg}$ (488-1651) which included both bolus doses and infusions, with a median duration of treatment of 24 hours (16-40 hours). The median delay to infusion after bolus was 2 hours (1-4).

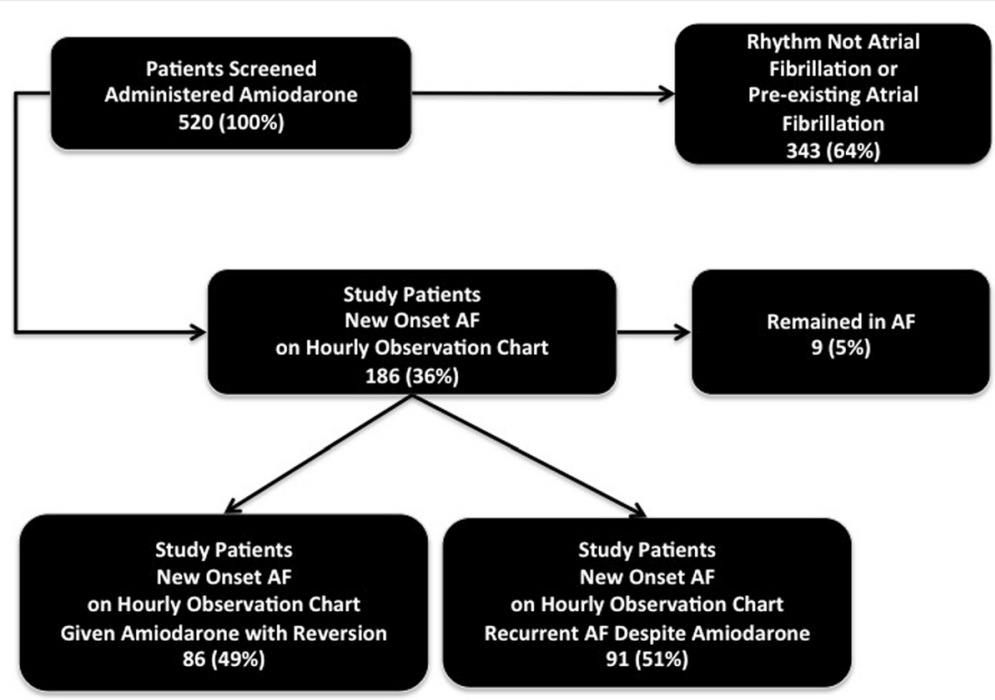

Fig. 1 Consort Diagram for Atrial Fribrillation Patients Admitted to ICU. AF Atrial fibrillation 
Table 1 Patient characteristics

\begin{tabular}{|c|c|c|c|c|}
\hline Parameter & $\begin{array}{l}\text { No recurrence of AF } \\
(n=86)\end{array}$ & $\begin{array}{l}\text { Recurrence of AF } \\
(n=91)\end{array}$ & $\begin{array}{l}\text { Total } \\
(n=177)\end{array}$ & $P$ \\
\hline Age (years) & $65(57-75)$ & $71(61-76)$ & $69(60-75)$ & 0.10 \\
\hline Male & $53(61)$ & $60(66)$ & $113(64)$ & 0.64 \\
\hline APACHE ॥ & $21(17-26)$ & $23(17-29)$ & $22(17-28)$ & 0.28 \\
\hline SAPS ॥ & $39(30-49)$ & $44(31-58)$ & $41(31-53)$ & 0.12 \\
\hline ICU LOS (days) & $6(3-12)$ & $8(4-16)$ & $7(4-13)$ & 0.05 \\
\hline Hospital LOS (days) & $21(12-46)$ & $31(18-70)$ & $25(13-58)$ & 0.09 \\
\hline ICU Outcome & & & & 0.83 \\
\hline Died & $10(12)$ & $13(14)$ & $23(13)$ & \\
\hline Discharged & $75(87)$ & $77(85)$ & $152(86)$ & \\
\hline Transferred & $1(1)$ & $1(1)$ & $2(1)$ & \\
\hline Hospital Outcome & & & & 0.08 \\
\hline Died & $22(26)$ & $25(27)$ & $47(27)$ & \\
\hline Discharged Home & $44(51)$ & $37(41)$ & $81(46)$ & \\
\hline Transferred & $17(20)$ & $29(32)$ & $46(26)$ & \\
\hline Not recorded & $3(3)$ & $0(0)$ & $3(2)$ & \\
\hline Weight (kg) & $\begin{array}{l}80(69-100) \\
(n=79)\end{array}$ & $\begin{array}{l}75(65-90) \\
(n=87)\end{array}$ & $\begin{array}{l}78(66-95) \\
(n=166)\end{array}$ & 0.15 \\
\hline Height (cm) & $\begin{array}{l}170(165-175) \\
(n=76)\end{array}$ & $\begin{array}{l}170(162-175) \\
(n=84)\end{array}$ & $\begin{array}{l}170(162-175) \\
(n=160)\end{array}$ & 0.73 \\
\hline Body Mass Index & $\begin{array}{l}28(25-34) \\
(n=76)\end{array}$ & $\begin{array}{l}26(24-31) \\
(n=84)\end{array}$ & $\begin{array}{l}28(24-33) \\
(n=160)\end{array}$ & 0.06 \\
\hline Charlson Score & $2(1-4)$ & $3(2-5)$ & $2(1-4)$ & 0.01 \\
\hline Concurrent use of digoxin* & $9(10)$ & $25(27)$ & $34(19)$ & 0.004 \\
\hline Concurrent use of beta-blockers & $46(53)$ & $42(46)$ & $88(50)$ & 0.37 \\
\hline
\end{tabular}

* All patients receiving digoxin were also on a beta-blocker

Values are shown as median (IQR) or number (\%) as appropriate

AF Atrial fibrillation, APACHE Acute Physiology and Chronic Health Evaluation, BMI body mass index, ICU intensive care unit, LOS length of stay, SAPS Simplified

Acute Physiology Score

Patients receiving a bolus of amiodarone or an infusion only were more likely to have a recurrence of AF $(P<0.001)$. Patients with recurrence received more amiodarone overall, which may be due to persisting risk factors requiring longer treatment or greater amiodarone dosing.

In logistic regression modelling, patients who were receiving inotropes during treatment for $\mathrm{AF}$ were found to have an increased risk of recurrence when amiodarone was stopped prior to cessation of inotrope infusion $(P<0.001$; Table 5$)$. Receiving amiodarone for the entire duration of the ICU stay once AF developed was associated with a lower risk of recurrence of $\operatorname{AF}(P<0.001)$, as was receiving an initial bolus of amiodarone followed by an infusion over 24 hours, rather than just an infusion without a bolus dose $(P=0.02)$. If patients had a prior history of congestive cardiac failure, they were more likely to have a recurrence $(P=0.04)$. The diagnosis of SIRS was also a significant predictor of AF recurrence $(P=0.02)$. Although the use of digoxin was associated with recurrence, this was not found to be an independent predictor and more in keeping with the use of an additional agent to control the recurrence.

\section{Discussion}

We identified several clinically significant factors associated with recurrence of new-onset AF in our cohort of patients. Ceasing amiodarone in patients who were still receiving inotrope infusions was associated with AF recurrence. Patients who remained on amiodarone treatment for the entire duration of their ICU stay once AF developed were less likely to have recurrence of $\mathrm{AF}$. Similarly, AF recurrence was less likely in patients in whom a bolus dose and infusion of amiodarone was used rather than an infusion without an initial bolus. The risk of recurrence was also significantly associated with a prior history of congestive cardiac failure and the presence of SIRS.

The electrophysiological changes that occur in the atrium in AF have been extensively studied but remain 
Table 2 Comorbidities

\begin{tabular}{|c|c|c|c|c|}
\hline Comorbidity & $\begin{array}{l}\text { No recurrent AF } \\
(n=86)\end{array}$ & $\begin{array}{l}\text { Recurrent AF } \\
(n=91)\end{array}$ & $\begin{array}{l}\text { Total } \\
(n=177)\end{array}$ & $P$ \\
\hline Myocardial infarction & $17(20)$ & $26(29)$ & $43(24)$ & 0.22 \\
\hline Congestive cardiac failure & $6(7)$ & $16(18)$ & $22(12)$ & 0.04 \\
\hline Peripheral vascular disease & $14(16)$ & $26(29)$ & $40(23)$ & 0.07 \\
\hline Cerebrovascular disease & $13(15)$ & $6(7)$ & $19(11)$ & 0.09 \\
\hline Dementia & $4(5)$ & $1(1)$ & $5(3)$ & 0.20 \\
\hline Chronic pulmonary disease & $26(30)$ & $32(35)$ & $58(33)$ & 0.52 \\
\hline Connective tissue disease & $4(5)$ & $7(8)$ & $11(6)$ & 0.54 \\
\hline Peptic ulcer disease & $5(6)$ & $4(4)$ & $9(5)$ & 0.74 \\
\hline Mild liver disease & $3(3)$ & $6(7)$ & $9(5)$ & 0.74 \\
\hline Diabetes mellitus & $14(16)$ & $11(12)$ & $25(14)$ & 0.52 \\
\hline Moderately severe renal disease & $14(16)$ & $16(18)$ & $30(17)$ & 0.84 \\
\hline Diabetes mellitus - severe & $3(3)$ & $3(3)$ & $6(3)$ & 1.00 \\
\hline Any tumour & $11(13)$ & $14(15)$ & $25(14)$ & 0.67 \\
\hline Leukaemia & $3(3)$ & $9(10)$ & $12(7)$ & 0.13 \\
\hline Lymphoma & $2(2)$ & $2(2)$ & $4(2)$ & 1.00 \\
\hline Moderately severe liver disease & $1(1)$ & $2(2)$ & $3(2)$ & 1.00 \\
\hline Metastatic tumour & $3(3)$ & $9(10)$ & $12(7)$ & 0.13 \\
\hline SIRS & $47(55)$ & $62(68)$ & $109(62)$ & 0.09 \\
\hline Sepsis & $28(33)$ & $36(40)$ & $64(36)$ & 0.35 \\
\hline Ischaemic heart disease & $23(27)$ & $35(38)$ & $58(33)$ & 0.11 \\
\hline Hypertension & $50(58)$ & $56(62)$ & $106(60)$ & 0.65 \\
\hline Hypokalaemia & $29(34)$ & $31(34)$ & $60(34)$ & 1.00 \\
\hline Rheumatic heart disease & $2(2)$ & $0(0)$ & $2(1)$ & 0.24 \\
\hline Mitral valve disease & $7(8)$ & $2(2)$ & $9(5)$ & 0.09 \\
\hline Haemochromatosis & $1(1)$ & $1(1)$ & $2(1)$ & 1.00 \\
\hline
\end{tabular}

Values are shown as number (\%)

AF Atrial fibrillation, SIRS systemic inflammatory response syndrome

poorly understood, especially in the critically ill. It is thought that AF is initiated through focal (ectopic) activity in the left atrium near the pulmonary veins. The mechanism underlying this is believed to be premature firing of action potentials through acceleration of phase four depolarisation (abnormal automaticity) as well as early and delayed after-depolarisations (EAD and DAD, respectively) [35]. Both of these mechanisms have been shown to be initiated through adrenergic stimulation with catecholamines [35]. It has also been shown that $\mathrm{AF}$ is maintained through a process termed multiple wavelet intramural re-entry, in which there is a continuous re-entry circuit formed within the atria $[35,36]$. This effect has been shown to be stimulated by adrenergic drugs [35, 36, 37]. In keeping with these findings, we have shown that patients on inotrope infusions had higher rates of recurrence when amiodarone was ceased while these agents continued.
Amiodarone is considered to be the drug of choice for treating AF [16], although there is little evidence of its utility in a general ICU population. Despite having beta adrenergic blocking activity, it is unlikely to affect catecholamine dose requirements [23]. To our knowledge, only two randomised controlled trials have specifically assessed the use of amiodarone for treatment of AF in general ICU patients. Chapman et al. [17] evaluated the efficacy of amiodarone for AF in non-cardiothoracic critically ill patients in a randomised controlled trial compared with procainamide. The dose of amiodarone in this study was based on weight $(3 \mathrm{mg} / \mathrm{kg}$ bolus followed by $10 \mathrm{mg} / \mathrm{kg} / 24$ hours) and the rate of conversion into sinus rhythm was $70 \%$ in the amiodarone group. Drugs were given for a minimum of 72 hours. We found that patients who developed AF and were treated with amiodarone for the entire duration of their ICU admission were less likely to have a recurrence of $\mathrm{AF}$, as at this 
Table 3 Summary of physiological parameters in patients with recurrent atrial fibrillation

\begin{tabular}{|c|c|c|c|}
\hline Parameter & $\begin{array}{l}\text { On day atrial fibrillation } \\
\text { initially reverted }\end{array}$ & $\begin{array}{l}\text { On day atrial } \\
\text { fibrillation recurred }\end{array}$ & $P$ \\
\hline 24-hour fluid balance (ml) & $\begin{array}{l}963(223-2010) \\
(n=82)\end{array}$ & $\begin{array}{l}173(-847 \text { to } 1304) \\
(n=76)\end{array}$ & 0.001 \\
\hline CVP $\min \left(\mathrm{cmH}_{2} \mathrm{O}\right)$ & $\begin{array}{l}7(4-10) \\
(n=57)\end{array}$ & $\begin{array}{l}6(3-9) \\
(n=64)\end{array}$ & 0.75 \\
\hline CVP $\max \left(\mathrm{cmH}_{2} \mathrm{O}\right)$ & $\begin{array}{l}19(14-22) \\
(n=57)\end{array}$ & $\begin{array}{l}18(13-22) \\
(n=64)\end{array}$ & 0.10 \\
\hline $\mathrm{K} \min (\mathrm{mmol} / \mathrm{L})$ & $\begin{array}{l}4.2(3.8-4.5) \\
(n=81)\end{array}$ & $\begin{array}{l}4.2(4.0-4.6) \\
(n=73)\end{array}$ & 0.18 \\
\hline $\mathrm{K} \max (\mathrm{mmol} / \mathrm{L})$ & $\begin{array}{l}4.3(4.1-4.7) \\
(n=81)\end{array}$ & $\begin{array}{l}4.4(4.1-4.7) \\
(n=73)\end{array}$ & 0.86 \\
\hline $\mathrm{Mg} \min (\mathrm{mmol} / \mathrm{L})$ & $\begin{array}{l}1.07(0.91-1.26) \\
(n=81)\end{array}$ & $\begin{array}{l}1.03(0.92-1.18) \\
(n=71)\end{array}$ & 0.23 \\
\hline Mg max (mmol/L) & $\begin{array}{l}1.15(0.99-1.34) \\
(n=81)\end{array}$ & $\begin{array}{l}1.08(0.96-1.24) \\
(n=71)\end{array}$ & 0.03 \\
\hline Temperature $\min \left({ }^{\circ} \mathrm{C}\right)$ & $\begin{array}{l}36.5(36-37.1) \\
(n=82)\end{array}$ & $\begin{array}{l}36.4(36-36.9) \\
(n=76)\end{array}$ & 0.34 \\
\hline Temperature $\max \left({ }^{\circ} \mathrm{C}\right)$ & $\begin{array}{l}37.8(37.1-38.4) \\
(n=82)\end{array}$ & $\begin{array}{l}37.6(37-38.4) \\
(n=76)\end{array}$ & 0.36 \\
\hline WCC $\min \left(\times 10^{9} / \mathrm{L}\right)$ & $\begin{array}{l}10.7(7.5-15.6) \\
(n=78)\end{array}$ & $\begin{array}{l}12.2(9.8-18.2) \\
(n=71)\end{array}$ & 0.01 \\
\hline WCC $\max \left(\times 10^{9} / \mathrm{L}\right)$ & $\begin{array}{l}11.3(7.8-15.9) \\
(n=78)\end{array}$ & $\begin{array}{l}12.5(9.8-18.7) \\
(n=71)\end{array}$ & 0.27 \\
\hline
\end{tabular}

Values are shown as median (IQR), with missing data for differing patient numbers

CVP Central venous pressure, $K$ potassium concentration, max maximum, Mg magnesium concentration, min minimum, WCC white cell count

time inciting factors presumably had resolved. Our study supports the use of an adequate loading dose followed by an infusion of amiodarone, with continuation until inotropes are ceased, in order to reduce the risk of recurrence of $\mathrm{AF}$.

A longer duration of treatment with amiodarone may result in a greater likelihood of rhythm stability. Moran et al. [18] performed a randomised controlled trial assessing the efficacy of amiodarone compared with magnesium sulphate. This study found that amiodarone was successful at converting AF into sinus rhythm in 7/14 (50 \%) patients. Interestingly, this study found amiodarone to be less effective than Chapman et al. [17], despite higher doses of amiodarone being used $(5 \mathrm{mg} / \mathrm{kg}$ bolus followed by $10 \mathrm{mg} / \mathrm{kg} / 24$ hours). Both these studies included tachyarrhythmias other than AF, and may account for the differences in rates of reversion to sinus rhythm. Both of these trials lacked a follow-up duration suitable to identify patients with recurrences, nor explored recurrence risk factors.

A wide range of dosing regimens are used for treating AF (3-7.5 mg/ $/ \mathrm{kg}$ bolus and follow on infusions of 1200 $1500 \mathrm{mg} / 24$ hours or $10 \mathrm{mg} / \mathrm{kg} / 24$ hours) [17-20, 23]. This lack of consensus on the best dosing regimen was reflected in our results. There was no uniform dosing
Table 4 Amiodarone therapy summary

\begin{tabular}{|c|c|c|c|c|}
\hline Parameter & $\begin{array}{l}\text { No AF recurrence } \\
(n=86)\end{array}$ & $\begin{array}{l}\text { AF recurrence } \\
(n=91)\end{array}$ & $\begin{array}{l}\text { Total } \\
(n=177)\end{array}$ & $P$ \\
\hline Amiodarone boluses & & & & 0.07 \\
\hline 0 & $43(42)$ & $19(25)$ & $62(35)$ & \\
\hline 1 & $51(50)$ & $47(61)$ & $98(55)$ & \\
\hline 2 & $5(5)$ & $7(9)$ & $12(7)$ & \\
\hline 3 & $2(2)$ & $3(4)$ & $5(3)$ & \\
\hline Amiodarone dosing & & & & $<0.001$ \\
\hline Bolus only & $3(3)$ & $20(23)$ & $23(13)$ & \\
\hline Infusion only & $43(43)$ & $19(25)$ & $62(35)$ & \\
\hline Bolus and infusion & $40(47)$ & $52(57)$ & $92(52)$ & \\
\hline $\begin{array}{l}\text { Delay to infusion } \\
\text { after bolus (hours) }\end{array}$ & $\begin{array}{l}2(1-3) \\
(n=29)\end{array}$ & $\begin{array}{l}2(1-6) \\
(n=45)\end{array}$ & $\begin{array}{l}2(1-4) \\
(n=74)\end{array}$ & 0.48 \\
\hline $\begin{array}{l}\text { Total dose } \\
\text { amiodarone (mg) }\end{array}$ & $\begin{array}{l}702 \\
(300-1117)\end{array}$ & $\begin{array}{l}1366 \\
(752-2711)\end{array}$ & $\begin{array}{l}905 \\
(488-1651)\end{array}$ & $<0.001$ \\
\hline $\begin{array}{l}\text { Infusion time } \\
\text { (hours) }\end{array}$ & $20(12-28)$ & $31(20-58)$ & $24(16-40)$ & $<0.001$ \\
\hline $\begin{array}{l}\text { Continuing to } \\
\text { receive inotropes } \\
\text { with amiodarone } \\
\text { ceased }\end{array}$ & $\begin{array}{l}0(0) \\
(n=2)\end{array}$ & $\begin{array}{l}23(66) \\
(n=35)\end{array}$ & $\begin{array}{l}37(100) \\
(n=37)\end{array}$ & 0.14 \\
\hline
\end{tabular}

strategy used and $35 \%$ of patients did not receive a loading dose. Patients receiving an amiodarone bolus typically received an "ampoule" of $300 \mathrm{mg}$ regardless of weight and had a median delay in a follow-on infusion of 2 hours. Patients receiving a loading dose and an infusion were less likely to have recurrence when compared to those in whom only a continuous infusion without a bolus was administered.

Several studies have reported risk factors for development of AF in the critically ill patient, mainly in the cardiothoracic surgical setting. Cardiovascular disease has previously been implicated in the development of AF. Factors which are predictive of increasing risk include coronary artery disease [4], cardiomegaly [4], low left ventricular ejection fraction $[9,12]$, pre-existing cardiovascular disease [13], and right ventricular dysfunction [12]. Other studies have suggested inflammatory processes as a risk factor for AF, with SIRS [5], sepsis [5] and a raised C reactive protein [6] being implicated. Consistent with these, we found AF recurrence associated with congestive cardiac failure, altered fluid balance, low serum magnesium and an elevated white cell count, the latter supportive of the association with SIRS. The two patients with hyperthyroidism were not suspected clinically of such at the time of amiodarone administration.

Physiologic disturbances, such as electrolyte derangements, commonly precipitate rhythm disorders such as AF [4]. We assessed maximum and minimum values, as the timing of the measures in this retrospective analysis 
Table 5 Logistic regression of risk factors for recurrence of atrial fibrillation

\begin{tabular}{|c|c|c|c|}
\hline Variable & OR & $95 \% \mathrm{Cl}$ & $P$ \\
\hline \multicolumn{4}{|l|}{ Univariate regression } \\
\hline History congestive cardiac failure & 2.84 & $1.05-7.65$ & 0.04 \\
\hline Peripheral vascular disease & 2.06 & $0.99-4.27$ & 0.05 \\
\hline Cerebrovascular disease & 0.40 & $0.14-1.10$ & 0.07 \\
\hline SIRS & 1.77 & $0.96-3.27$ & 0.07 \\
\hline Ischaemic heart disease & 1.71 & $0.91-3.23$ & 0.10 \\
\hline Mitral valve disease & 0.25 & $0.05-1.26$ & 0.09 \\
\hline Metastatic tumour & 3.03 & $0.79-11.6$ & 0.11 \\
\hline Leukaemia & 3.03 & $0.79-11.61$ & 0.11 \\
\hline Age & 1.02 & $1.00-1.04$ & 0.12 \\
\hline Body mass index & 0.96 & $0.92-1.00$ & 0.06 \\
\hline Concurrent use of beta-blockers & 1.50 & $0.83-2.73$ & 0.18 \\
\hline Concurrent use of digoxin* & 5.06 & $2.20-11.67$ & $<0.001$ \\
\hline $\begin{array}{l}\text { Ceasing amiodarone while on inotrope } \\
\text { infusion }\end{array}$ & 8.76 & $3.58-21.4$ & $<0.001$ \\
\hline $\begin{array}{l}\text { Delay of infusion after bolus dose of } \\
\text { amiodarone }\end{array}$ & 1.86 & $1.02-3.44$ & 0.05 \\
\hline $\begin{array}{l}\text { Receiving a bolus dose and infusion of } \\
\text { amiodarone }\end{array}$ & 0.44 & $0.23-0.86$ & 0.02 \\
\hline $\begin{array}{l}\text { Remaining on amiodarone to discharge } \\
\text { from ICU }\end{array}$ & 0.02 & $0.01-0.05$ & $<0.001$ \\
\hline \multicolumn{4}{|l|}{ Multivariate regression } \\
\hline $\begin{array}{l}\text { Ceasing amiodarone while on inotrope } \\
\text { infusion }\end{array}$ & 5.89 & $1.86-18.6$ & 0.003 \\
\hline $\begin{array}{l}\text { Remaining on amiodarone for duration } \\
\text { of ICU admission }\end{array}$ & 0.01 & $0.003-0.04$ & $<0.001$ \\
\hline SIRS & 4.21 & $1.32-13.4$ & 0.02 \\
\hline \multicolumn{4}{|c|}{ Hosmer and Lemeshow Goodness of Fit $\mathrm{Chi}^{2} 7.19, P=0.21$} \\
\hline \multicolumn{4}{|l|}{ Area under ROC curve (discrimination) 0.92} \\
\hline
\end{tabular}

* All patients receiving digoxin also were on a beta-blocker $\mathrm{Cl}$ Confidence interval, ICU intensive care unit, OR odds ratio, $R O C$ receiver operating characteristic, SIRS systemic inflammatory response syndrome

were quite variable, potentially masking an association if daily averaged or time averaging values were used. Abnormal values are unlikely to persist for long without correction in an intensive care environment. Our study examined patients once they developed AF, and hence electrolytes and other physiologic variables would presumably be kept strictly within normal limits. Positive fluid balance potentially causing atrial stretch is well recognised as a risk factor for AF. As for patients with recurrence, deciding on the relevant cumulative fluid balance to compare patients with and without recurrence at a similar point of time in their disease is difficult. In our study, a less positive 24-hour fluid balance at the time of AF recurrence was noted. Dynamic changes in the degree of atrial stretch may be just as important as any specific degree of stretch at a single point in time as a cause for AF. This would be better assessed prospectively with more objective assessment of cardiovascular fill such as inferior vena cava dimensions and changes with respiration on ultrasound imaging, as well as the effect of the time frame of changes in volume status.

\section{Strengths and limitations}

Our study was performed in a tertiary referral hospital with a wide range of specialist surgical and medical services excluding cardiac surgery. Specialist services included bone marrow transplantation, obstetric, trauma and burns units. Our findings are unique as no previous studies have specifically examined factors leading to AF recurrence once successfully treated.

Our study can only make inference about patients receiving amiodarone, as patients who received other pharmacological treatments and electrical cardioversion without amiodarone were excluded. The effects of concomitant use of beta-blockers or digoxin were not significant in multivariate modelling. Other treatment options such as intravenous diltiazem are not available in Australia [38].

Other than in the setting of paroxysmal AF [39], there is no agreed time period for which the patient must remain in sinus rhythm following cardioversion from $\mathrm{AF}$ in order to define this as successful. In this study, we pragmatically used 12 hours of sinus rhythm as the minimal time for successful treatment with amiodarone. This reflects the acuteness of illness within an ICU and is an average of studies of AF in the critically ill where the efficacy of therapy has been assessed within 2 hours and 24 hours of drug administration [40].

Our study had a relatively small sample size as our focus was on the use of amiodarone. As such, only known risk factors were included in an attempt not to overfit the regression model. Ventilation parameters such as level of positive end-expiratory pressure were not considered as they often reflect fluid status and are unlikely to interact with recurrence. Early death may have been influenced by chance to detect AF recurrence; however, ICU duration of stay and the ICU mortality were similar with complete follow-up for the period of the ICU admission in both groups. Despite this, we were able to show statistically significant associations with recurrence of AF. Our project was also retrospective in nature, limiting the choice of variables to record for analysis. However, relevant clinical data were available and recorded prospectively in a systematic manner in an electronic clinical information system.

\section{Conclusion}

Patients with new-onset AF who are treated with amiodarone should receive a loading dose, immediately 
followed by an infusion. Clinicians should consider continuing amiodarone infusions in patients who are receiving inotropes until the inotrope is ceased. Patients who have pre-existing congestive cardiac failure or SIRS diagnosed on admission into ICU are at a greater risk of recurrence of AF. Vigilance of magnesium replacement, avoiding excessive volume depletion and the resolution of SIRS would appear a reasonable approach to limit AF recurrence, particularly as many known parameters are managed routinely within a tight range for patients in the ICU. A clear dosing guide is not available and further research is required to elicit the best dosing strategy.

\section{Abbreviations \\ AF: Atrial fibrillation; APACHE: Acute Physiology and Chronic Health Evaluation; BMI: Body mass index; DAD: Delayed after-depolarisation; EAD: Early after-depolarisation; ECG: Electrocardiogram; ICU: Intensive care unit; IQR: Interquartile range; SAPS: Simplified Acute Physiologic Score; SIRS: Systemic inflammatory response syndrome.}

\section{Competing interests}

The authors declare that they have no competing interest.

\section{Authors' contributions}

Study designed collaboratively by GM, AU, HB, PC and RB. Data collections carried out by GM, HB and PC. Data analysis by GM and RB. Manuscript preparation by $G M, A U, H B, P C$ and $R B$. All authors read and approved the final manuscript.

\section{Author details}

'School of Medicine, University of Queensland, Brisbane, QLD, Australia. 2Department of Intensive Care Medicine, Royal Brisbane \& Women's Hospital, Herston, Brisbane, QLD, Australia. ${ }^{3}$ Burns Trauma and Critical Care Research Centre, University of Queensland, Brisbane, QLD, Australia. ${ }^{4}$ Department of Intensive Care and Hyperbaric Medicine, The Alfred Hospital, Prahran, VIC, Australia. ${ }^{5}$ Department of Epidemiology and Preventive Medicine, Monash University, The Alfred Centre, Prahran, Melbourne, VIC, Australia.

\section{Received: 10 October 2015 Accepted: 22 February 2016}

Published online: 02 April 2016

\section{References}

1. Arora S, Lang I, Nayyar V, Stachowski E, Ross DL. Atrial fibrillation in a tertiary care multidisciplinary intensive care unit-incidence and risk factors. Anaesth Intensive Care. 2007;35:707-13.

2. Artucio H, Pereira M. Cardiac arrhythmias in critically ill patients: epidemiologic study. Crit Care Med. 1990;18:1383-8.

3. Brathwaite $D$, Weissman C. The new onset of atrial arrhythmias following major noncardiothoracic surgery is associated with increased mortality. Chest. 1998:114:462-8.

4. Burris JM, Subramanian A, Sansgiry S, Palacio CH, Bakaeen FG, Awad SS. Perioperative atrial arrhythmias in noncardiothoracic patients: a review of risk factors and treatment strategies in the veteran population. Am J Surg. 2010;200:601-5

5. Knotzer H, Mayr A, Ulmer H, et al. Tachyarrhythmias in a surgical intensive care unit: a case-controlled epidemiologic study. Intensive Care Med. 2000;26:908-14.

6. Meierhenrich $\mathrm{R}$, Steinhilber E, Eggermann $\mathrm{C}$, et al. Incidence and prognostic impact of new-onset atrial fibrillation in patients with septic shock: a prospective observational study. Crit Care. 2010;14:R108.

7. Reinelt P, Karth GD, Geppert A, Heinz G. Incidence and type of cardiac arrhythmias in critically ill patients: a single center experience in a medicalcardiological ICU. Intensive Care Med. 2001;27:1466-73.

8. Salaria V, Mehta NJ, Abdul-Aziz S, Mohiuddin SM, Khan IA. Role of postoperative use of adrenergic drugs in occurrence of atrial fibrillation after cardiac surgery. Clin Cardiol. 2005;28:131-5.
9. Salman S, Bajwa A, Gajic O, Afessa B. Paroxysmal atrial fibrillation in critically ill patients with sepsis. J Intensive Care Med. 2008;23:178-83.

10. Dewar RI, Lip GY. Identification, diagnosis and assessment of atrial fibrillation. Heart (British Cardiac Society). 2007;93:25-8.

11. De Backer D, Biston P, Devriendt J, et al. Comparison of dopamine and norepinephrine in the treatment of shock. N Engl J Med. 2010;362:779-89.

12. Fleming $\mathrm{GA}$, Murray $\mathrm{KT}, \mathrm{Yu} \mathrm{C}$, et al. Milrinone use is associated with postoperative atrial fibrillation after cardiac surgery. Circulation. 2008;118:1619-25

13. Seguin $P$, Signouret $T$, Laviolle $B$, Branger $B$, Malledant $Y$. Incidence and risk factors of atrial fibrillation in a surgical intensive care unit. Crit Care Med. 2004:32:722-6.

14. Christian SA, Schorr C, Ferchau L, Jarbrink ME, Parrillo JE, Gerber DR. Clinical characteristics and outcomes of septic patients with new-onset atrial fibrillation. J Crit Care. 2008;23:532-6.

15. Shaver CM, Chen W, Janz DR, et al. Atrial fibrillation is an independent predictor of mortality in critically ill patients. Crit Care Med. 2015;43:2104-11.

16. Arrigo M, Bettex D. Management of atrial fibrillation in critically ill patients. Crit Care Res Pract. 2014;2014:840615.

17. Chapman MJ, Moran JL, O'Fathartaigh MS, Peisach AR, Cunningham DN. Management of atrial tachyarrhythmias in the critically ill: a comparison of intravenous procainamide and amiodarone. Intensive Care Med. 1993;19:48-52.

18. Moran JL, Gallagher J, Peake SL, Cunningham DN, Salagaras M, Leppard P. Parenteral magnesium sulfate versus amiodarone in the therapy of atrial tachyarrhythmias: a prospective, randomized study. Crit Care Med. 1995:23:1816-24.

19. Faniel R, Schoenfeld P. Efficacy of i.v. amiodarone in converting rapid atrial fibrillation and flutter to sinus rhythm in intensive care patients. Eur Heart J. 1983:4:180-5.

20. Sleeswijk ME, Tulleken JE, Van Noord T, Meertens JH, Ligtenberg JJ, Zijlstra JG. Efficacy of magnesium-amiodarone step-up scheme in critically ill patients with new-onset atrial fibrillation: a prospective observational study. J Intensive Care Med. 2008;23:61-6.

21. Clemo HF, Wood MA, Gilligan DM, Ellenbogen KA. Intravenous amiodarone for acute heart rate control in the critically ill patient with atrial tachyarrhythmias. Am J Cardiol. 1998;81:594-8.

22. Hofmann R, Steinwender C, Kammler J, Kypta A, Leisch F. Effects of a high dose intravenous bolus amiodarone in patients with atrial fibrillation and a rapid ventricular rate. Int J Cardiol. 2006;110:27-32.

23. Holt AW. Hemodynamic responses to amiodarone in critically ill patients receiving catecholamine infusions. Crit Care Med. 1989;17:1270-6.

24. Kumar A. Intravenous amiodarone for therapy of atrial fibrillation and flutter in critically ill patients with severely depressed left ventricular function. Southern Med J. 1996;89:779-85.

25. Sleeswijk ME, Van Noord T, Tulleken JE, Ligtenberg JJ, Girbes AR, Zijlstra JG. Clinical review: treatment of new-onset atrial fibrillation in medical intensive care patients-a clinical framework. Crit Care. 2007;11:233.

26. Bone RC, Balk RA, Cerra FB, et al. Definitions for sepsis and organ failure and guidelines for the use of innovative therapies in sepsis. The ACCP/SCCM Consensus Conference Committee. American College of Chest Physicians/ Society of Critical Care Medicine. Chest. 1992;101:1644-55.

27. Dellinger RP, Levy MM, Carlet JM, et al. Surviving Sepsis Campaign: international guidelines for management of severe sepsis and septic shock: 2008. Crit Care Med. 2008:36:296-327.

28. Global Database on Body Mass Index. 2012. http://www. assessmentpsychology.com/icbmi.htm. Accessed date 5/3/2016

29. Knaus WA, Draper EA, Wagner DP, Zimmerman JE. APACHE II: a severity of disease classification system. Crit Care Med. 1985;13:818-29.

30. Le Gall JR, Lemeshow S, Saulnier F. A new Simplified Acute Physiology Score (SAPS II) based on a European/North American multicenter study. JAMA. 1993;270:2957-63.

31. Charlson ME, Pompei P, Ales KL, MacKenzie CR. A new method of classifying prognostic comorbidity in longitudinal studies: development and validation. J Chron Dis. 1987:40:373-83.

32. Ferrieri P. Proceedings of the Jones Criteria workshop. Circulation. 2002;106:2521-3.

33. Fletcher LM, Halliday JW. Haemochromatosis: understanding the mechanism of disease and implications for diagnosis and patient management following the recent cloning of novel genes involved in iron metabolism. J Intern Med. 2002;251:181-92 
34. The Heart Foundation. Guide to management of hypertension 2008 Assessing and managing raised blood pressure in adults Uodates 2010. Phillip. ACT. Australia: National Heart Foundation of Australia; 2010.

35. Workman AJ. Cardiac adrenergic control and atrial fibrillation. Naunyn Schmiedeberg's Arch Pharmacol. 2010;381:235-49.

36. Waldo AL. Mechanisms of atrial fibrillation, atrial flutter, and ectopic atrial tachycardia-a brief review. Circulation. 1987;75:lii37-40.

37. Kalman JM, Munawar M, Howes LG, et al. Atrial fibrillation after coronary artery bypass grafting is associated with sympathetic activation. Ann Thorac Surg. 1995;60:1709-15.

38. Delle Karth G, Geppert A, Neunteufl T, et al. Amiodarone versus diltiazem for rate control in critically ill patients with atrial tachyarrhythmias. Crit Care Med. 2001;29:1149-53.

39. Fuster V, Ryden LE, Cannom DS, et al. 2011 ACCF/AHA/HRS focused updates incorporated into the ACC/AHA/ESC 2006 Guidelines for the management of patients with atrial fibrillation: a report of the American College of Cardiology Foundation/American Heart Association Task Force on Practice Guidelines developed in partnership with the European Society of Cardiology and in collaboration with the European Heart Rhythm Association and the Heart Rhythm Society. J Am Coll Cardiol. 2011;57:e101-98.

40. Yoshida T, Fujii T, Uchino S, Takinami M. Epidemiology, prevention, and treatment of new-onset atrial fibrillation in critically ill: a systematic review. J Intensive Care. 2015;3:19.

\section{Submit your next manuscript to BioMed Central and we will help you at every step:}

- We accept pre-submission inquiries

- Our selector tool helps you to find the most relevant journal

- We provide round the clock customer support

- Convenient online submission

- Thorough peer review

- Inclusion in PubMed and all major indexing services

- Maximum visibility for your research

Submit your manuscript at www.biomedcentral.com/submit

) Biomed Central 